IJBPAS, December, 2020, 9(12): 3435-3450

ISSN: $2277-4998$

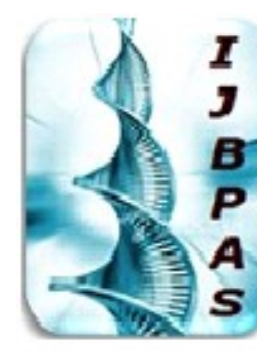
International Journal of Bhology, Pharmacy and Allied Sciences (IJBPAS)
'A Bridge Betuen Caboratory and QRendo'

\title{
Www.iibpas.com
}

\section{EPILEPSY AND ANTIEPILEPTIC DRUGS - A COMPREHENSIVE REVIEW}

\section{KOMALA $M^{* 1}$, SATHESH KUMAR $\mathrm{S}^{1}$, PADMAVATHY $\mathrm{J}^{1}$, PAVITHRA $\mathrm{K}^{2}$ AND}

\section{ARTHUR M ${ }^{2}$}

${ }^{1}$ Department of Pharmaceutics, School of Pharmaceutical Sciences, Vels Institute of Science, Technology and Advanced Studies, Pallavaram, Chennai, Tamilnadu, India

${ }^{2}$ Master of Pharmacy, Department of Pharmaceutics, School of Pharmaceutical Sciences, Vels Institute of Science, Technology and Advanced Studies, Pallavaram, Chennai, Tamilnadu, India

*Corresponding author: Dr. M. Komala: E Mail: komala.pharmacy@gmail.com;

Telephone: $+91-9840697473$

Received $19^{\text {th }}$ April 2020; Revised $9^{\text {th }}$ May 2020; Accepted $11^{\text {th }}$ June 2020; Available online $1^{\text {st }}$ Dec. 2020

https://doi.org/10.31032/IJBPAS/2020/9.12.5289

\begin{abstract}
Epilepsy is one of the most common and disabling neurological disorders of the brain influencing approximately 50 million people around the world disorder affecting all groups of ages. There are nearly 125,000 new cases of epilepsy each year and about $30 \%$ of patients are less than 18 years old. Several epilepsy diagnosis and treatment advances have recently been introduced providing pharmacists with tremendous opportunities to help improve drug therapy for epilepsy and various advanced drugs each with specific health, effectiveness and cost requirements, are available for treating seizures. The aim is to reduce the frequency and severity of seizures while reducing damage to the brain and other tissues by treating epilepsy with drugs. A variety of biological factors, particularly the blood-brain barrier, have severely limited drug access to the brain and contributed to the use of drugs loaded into the nanoparticles. This review attempts to describe the classification of seizures, epidemiology and available diagnostic procedures and the antiepileptic drugs used to treat epilepsy.
\end{abstract}

Keywords: Epilepsy; Seizures; Treatment; Anti-Epileptic Drugs; Mechanisms; Nano drug delivery 


\section{INTRODUCTION}

Epilepsy is one of the neurological disorder, described as repetitive (two or more) epileptic seizures resulting from sudden, excessive, abnormal synchronized neuronal discharges. The term "epilepsy" is acquired from the word "epilambanein", which means "to be seized" or "to be overwhelmed by surprise". On the account of damaged brain cells a serious condition arises, called epilepsy, which is indicated by the frequent seizures [1]. It is a long-term phenomenon, although seizures can occur sporadically or often sometime during lifetime. The external signs of epilepsy are termed as seizures which differs according to the portion of the brain damaged and how far the condition has progressed. This variability probably reflects the many underlying causes of epilepsy and a number of epilepsy syndromes, in which the clinical and pathological symptoms are distinctive [2]. Seizures may occur from a family history or after a brain injury, but the cause for epilepsy is unrevealed. It is also found that the existence of the diseases like diabetes increases the risk of developing epilepsy by three folds [3]. The epilepsy is symptomatic when it is recognized after a specific incident like asphyxia, head injury or meningitis. It is considered to be a neurological cramp which includes excessive neuron activity [4]. There are no distinctions between race geography or society, It develops in both genders and at all ages mostly prevailed in men upto $56 \%$ according to a study [5], particularly in children and elderly people [6]. In about one person per 103 , it is affected. One of the first brain disorders that had been identified was epilepsy. More than 3,000 years ago it was recorded in ancient Babylon. Over the years, some superstitions and misconceptions have been resulted by the strange behavior that has been triggered by some seizures. Epilepsy prevalence, measured with DALYs, accounts for 1 percent of the total worldwide disease burden, excluding the people with epilepsy (PWE) in India experience epilepsy due to social stigma and loneliness [7]. It was estimated that about $7 \%-8 \%$ of the people have experienced epileptic seizure for once in their lives. Epileptic convulsions have not completely explained the basic mechanism. The International League for Epilepsy (ILAE) and other organizations have launched "Out of the Darkness" in order to improve public awareness, treatment and prevention of epilepsy $[\mathbf{8 , 9}$ ).

\section{CLASSIFICATION OF SEIZURES}

An irregular, repetitive and hypersynchronous discharge of the neurons into 
your brain results in epileptic seizure. ILAE revised the classification of epileptic seizures in 1989 for the last time. This is important because the accurate detection of seizures and epilepsy is a key element for etiological diagnosis, appropriate treatment and precise prognosis [10]. The physiological characteristics of epilepsy and associated
EEG findings are the basis of this method. The etiology or cell substrates are not taken into account. The seizures are mainly classified in to three categories: (i) Partial seizures (ii) Generalized seizures and (iii) Unclassified seizures. Revised version of the ILAE classification of epileptic seizures are represented in Table 1 [11].

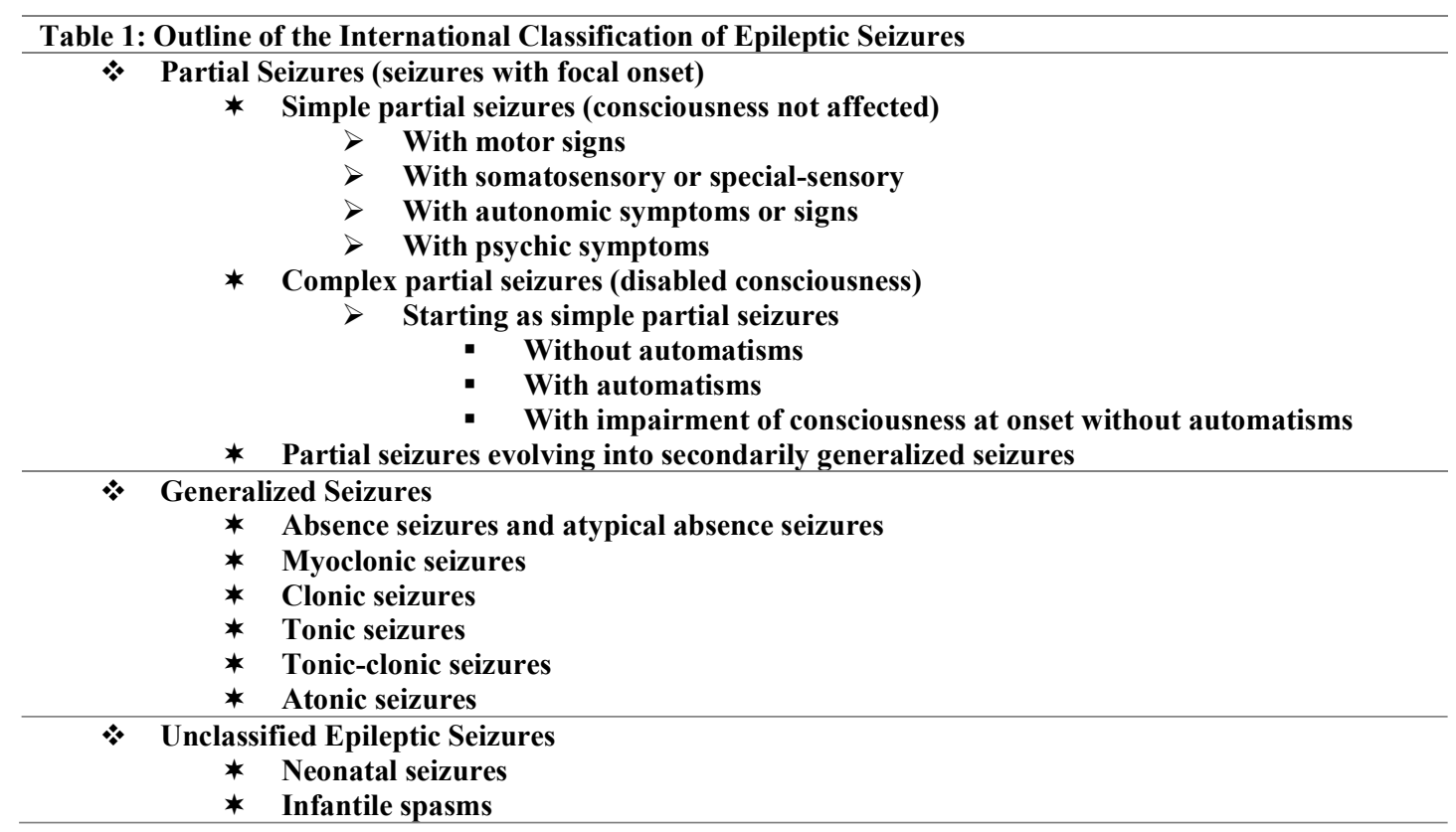

Partial seizures: Partial seizures are most common type of seizures and are limited to specific cerebral regions, usually involving only a certain brain area initially and display clinical or EEG symptoms of a cerebral hemisphere. They are further grouped in to simple or complex and develops in to generalized seizures. When the seizure occurs as a partial seizure, it then extends over the whole brain, it is said secondarily generalized partial seizure. The epileptic cycle is usually limited to neocortical systems in simple convulsions and the limbic system and brainstem are excluded. The loss of consciousness is reported in complex partial seizures. Such seizures may also be expressed as changes in somatic feeling, vision, balance, autonomic system olfactory 
changes, and hearing [12]. Such stimuli can cause a lot of discomfort to the patient.

Generalized Seizures: A complete loss of consciousness and an absence of aura characterizes the primary generalized seizures. They come about all of a sudden and unexpectedly and may harm themselves if the patients fall. Generalized convulsions are collectively triggered by both brain hemispheres [13]. Absence seizures commonly called as petit mal are defined by short span of consciousness without lack of postural function. Usually the seizure lasts for just seconds; the consciousness recovers as quickly as it had been lost [14]. General tonic clonic seizure is referred to as grandmal seizures. In the tonic stage where the person's arms and legs are tightened first and in the clonic phase, his or limbs and head begin to wrench. It can take minutes to hours to recover completely depending on the person [15]. Myoclonic seizures can cause body parts of an individual to twitch unexpectedly, his or her arm or leg. Atonic convulsions unexpectedly stiff a part or all of a person's body. Where their head may drop suddenly or fall down or even collapse entirely and fall down to the floor [14].

Unclassified Seizures: Not all forms of seizure are partial or generalized, as it seems in neonates and child seizures. In addition, neuronal function variations and development in the developing brain are likely to lead to some of those seizures that occur in neonates and infants [16].

\section{ETIOLOGY}

Seizures are caused by the change of normal excitement and inhibition equilibrium within the CNS and the dysfunction of the brain. As the different properties of the neuronal excitability can be controlled, it is not uncommon for this natural equilibrium to be disrupted in a wide range of ways [17].

When the acute condition was too serious or not properly treated, convulsions would have been long and persistent, resulting in brain anoxia, accompanied by epilepsy [18].

For children who otherwise are well, who are structurally disabled and who have genetic risk factors, seizures may be caused during high fever [19].

Epilepsy may occur in older patients with Alzheimer's disease and stroke. Almost 50\% of the risk of epilepsy is associated with a serious, deep traumatic brain injury.

Any region with an abnormative brain tissue (calcifications, cuts, or structural abnormalities) may be an area from which a "symptomatic epilepsy" - irregular neuronal activity takes place [20].

Conditions that most likely cause seizures include syncope and transient ischemic 
threats, some other probabilities include sudden fall of subarachnoid trauma, sleep disturbances, panic attacks and migraine disorders. As far many other idiopathic diseases such as diabetes are considered, the heritage form is complex, since many primary epilepsies are of hereditary origin [21].

\section{PATHOLOGY}

Symptomatic epilepsy is related to definable brain injuries. Such lesions include areas of neuronal loss and gliosis (scars) or other tissue loss symptoms. The extent of these injuries is not fully known [22]. The initial CNS damage, such as trauma, stroke, or infection and the first seizure, takes months to years. The injury can reduce the seizure threshold in the area under seizure until there is a spontaneous seizure [23]. A bilateral neuron loss in the CA1 segment of a hippocampus pyramidal cell layer extending into the adjoining areas of pyramidal and the underlying dentate gyrus is the most common histological finding in the brains of epileptic patients [24].

In several immature seizure disorders, the most specific genetic factor is also identified: i) absence of epilepsy with spike and wave discharges three per second; and (ii) Benign Rolandic Epilepsy of Childhood [BREC] [25] Idiopathic epilepsy can be caused by affecting neurotransmitter receptor in ionic canals in a particular group of epileptic disorders. Other neurological disorders including cognitive impairment coexist with seizures in patients with symptomatic epilepsy. The goal is to classify different susceptibility genes, which are the origin of the most common forms of idiopathic epilepsy [26].

\section{DIAGNOSTIC EVALUATION}

Following one or more paroxysmal events involving an epileptic seizure, individuals must perform a detailed clinical evaluation and a multi-stage diagnostic procedure, including medical history evaluation, physical examination, EEG, and neuroimaging [24]. Biochemical parameters can also be estimated for the epileptic patients [27]. However, much research is carried out to develop an automated detection using machine learning and magnetic resonance spectroscopy [28, 29]. Evaluation of infants and young children is more important as dysmorphic and cutaneous disorders can identify a variety of cerebral disorders that are highly characteristic and due to which epilepsy is triggered [30].

Family History: History is the key to identify epilepsy because the physical scanning is relatively undefined in most of the adults. The most significant aspect of all 
in a patient with frequent epilepsy is a carefully considered medical history [31].

EEG: In this process, the brain's electrical activity is detected amplified and recorded by a number of electrodes specifically placed on the head. During a seizure the EEG almost always displays irregular exudes. In the differentiation between partial and generalized seizures, it is often beneficial [32].

\section{Neuroimaging:}

A collection of laboratory studies, like a complete blood count, blood chemical samples, liver and thyroid function scans, an EEG, and a brain examination are normally included in the initial medical assessment, preferably by magnetic resonance imaging (MRI) [33]. For the evaluation of a patient suffering from a seizure, computed tomography (CT) and MRIs are important additions to a clinical test and the EEG. The techniques of neuroimaging are especially susceptible to structural losses for the central nervous system [31]. In a patient with selective seizures, abnormal neurological findings or EEG focus discharges, MRI is more likely to show an abnormality [34]. Quantitative volume analysis with computer assistance for temporary lobes can detect asymmetries, which cannot be easily seen when analyzing the scan visually. CT is useful for hemorrhages, calcification or tumors in acute conditions. Blood Oxygen Level Dependence (BOLD) is used to monitor and find language and memory through functional MRI (fMRI). Positron emission tomography (PET) is used in a number of research facilities to classify areas of the brain that cause convulsions [35].

\section{MANAGEMENT AND TREATMENT}

Management of epilepsy aims at eliminating or decreasing seizures, minimizing treatment effects, improving medical and neuropsychiatry comorbidity, and promoting excellent standard of life [36]. Usually neurologist prescribes medications to prevent seizure when epilepsy is diagnosed. Incase medications are failed, surgery, a special diet, complementary treatment, or stimulation of the vagus nerve could be tried. Treatment is designed to avoid further convulsions, prevent adverse effects [37].

\section{TREATMENT WITH ANTIEPILEPTIC DRUGS}

\section{Antiepileptic Drug Therapy:}

The main therapeutic assistance of patients has four aims: to prevent seizures or to minimize their frequency to the greatest extent possible, to avoid adverse long-term therapeutic effects and to help patients maintain or restore psychosocial and technical habits and to maintain basic 
lifestyles [38]. Only one drug should be given in beginning of the treatment. The drug choice is ideally dependent on the epileptic type and the type of seizure. A informed assessment of the probability of seizure reoccurrence and the adverse impacts of the drugs chosen should serve as basis for the choice for initiating AED treatment. For those who have to travel, continue to work or take care of family members, possible seizure can be distressing [39].

\section{Selection of Antiepileptic Therapy:}

At present, AEDs not only fail to monitor seizures in some patients, but also often cause adverse effects that vary from minimum disability to death caused by aplastic anemia or hepatic insufficiency [40]. Many studies are carried out to include the natural antiepileptic agents like curcumin to reduce the dose of the anti epileptic synthetic derivatives like phenytoin and sodium valproate and were proved to be effective [41]. Total seizures management in up to $50 \%$ of patients is generally recognized and another $25 \%$ of patients significantly improve [39]. AED is classified into riskassuming ones of relatively quantity and data insufficiency. This reinforces itself with an enhanced refusal of those who intake, the prescribed drugs of uncertain risk [42]. The latest data from the UK register of epilepsy indicate very clear dose-related effects with $5 \%$ risk with valproate exposure of $600 \mathrm{mg} /$ daily to $11 \%$ at more than $1000 \mathrm{mg}$. With $2 \%$ of $200 \mathrm{mg}$, lamotrigine had a lesser steep curve, which increased by over $400 \mathrm{mg}$ a day to $3.5 \%$. At $2 \%$ chance of risk with $500 \mathrm{mg}$ of Carbamazepine daily and 3\% risk for 500$1000 \mathrm{mg}$ and $5 \%$ for $1000 \mathrm{mg}$ [43].

I Monotherapy: The recommended primary treatment approach for epilepsy is antiepileptic drug monotherapy, as many patients can be treated with the first or second monotherapy successfully [44]. Most recent AEDs benefit from a more acceptable secured form and reduced adverse effects and drug interactions than their precursors. For certain patients like mothers, elderly and comorbid patients, monotherapy is especially advisable [45]. Latest focal clinical trials show that monotherapy use of AEDs of second generation has approved. From the past decade, AED's like lamotrigine, felbamate, gabapentine of second generation drugs have became available [46] and the two new additional ("third generation") AEDs, lacosamide and rufinamide, have emerged in the apparently rising accumulation of AEDs. Monotherapy cannot work if the option of AED for a specific patient type is not optimal. In patients who 
are not carefully assessed and advised by their doctors, monotherapy may fail [47].

II. Combination therapy: Add-on treatment is taken into account if monotherapies failed to efficiently regulate seizures. Through confirming the unmanageable diagnosis and the operational procedure in clinicians with epilepsy, treatment with AED should become optimized [48]. Add-on treatment is taken into account if monotherapies failed to efficiently regulate seizures. Through confirming the unmanageable diagnosis and the operational procedure in clinicians with epilepsy, treatment with AED should become optimized. A main plus another drug with several mechanisms of action has been the most successful combination. In human beings, combinations of a sodium blocker and a drug with multiple operational mechanisms can have synergistic effects. Combinations of more than three medicines are not suggested [49]. The recommended total daily dosage of topiramate is 200 to 400 mg / day in two separated doses for adults with partial seizures of 17 years of age or older. For the first week, the titration will start at $25 \mathrm{mg}$. The dose must then be raised at intervals of 1-2 weeks per day to achieve an optimal clinical response through increments of 1-3 mg / $\mathrm{kg}$ [50].

\section{MECHANISM OF ACTION OF ANTI EPILEPTIC DRUGS}

There are two important mechanisms through which AEDs act, they are:

- $\quad$ Reducing the release rate of neurons in the focus ("minimize initiation").

- Blocking the spread of excitation from the focus to other brain areas ("block spreading”) [51, 52].

These actions are caused by drug binding to one or more of the target brain molecules. Those objectives may include ion channels, neurotransmitters and metabolic enzymes for neurotransmitters. The overall effect is to alter the reactive effects of neurons and to reduce neuronal assemblies synchronization [53].

AEDs can be categorized into many groups, depending on the mechanism of action.

- Blockage of voltage-gated sodium channels (Phenytoin, valproic acid, lamotrigine)

- Increase of GABA inhibition (Barbiturates, benzodiazepines)

- Blockage of T- type Calcium channels.

- Decreased glutamate excitation (Felbamate, gabapentin) [54]

\section{ANTI EPILEPTIC DRUGS}

Some of the approved Antiepileptic Drugs (AEDs) used for the treatment of various 
types of epilepsy in the U.S. are listed in the occurrence of type of seizure.

Table 2. The drugs are used based on the

Table 2: Approved Antiepileptic Drugs for the Treatment of Seizures in the U.S. [44]

\begin{tabular}{|c|c|c|}
\hline Type of seizures & First line drugs & Alternative drugs \\
\hline $\begin{array}{c}\text { Primary generalized tonic clonic } \\
\text { seizures }\end{array}$ & $\begin{array}{l}\text { Valproic acid } \\
\text { Lamotrigine } \\
\text { Topiramate* }\end{array}$ & $\begin{array}{c}\text { Zonisamide } \\
\text { Phenytoin } \\
\text { Carbamazepine } \\
\text { Oxcarbazepine* } \\
\text { Phenobarbital } \\
\text { Primidone } \\
\text { Felbamate }\end{array}$ \\
\hline Absence seizures & $\begin{array}{l}\text { Valproic acid } \\
\text { Ethosuximide }\end{array}$ & $\begin{array}{l}\text { Lamotrigine* } \\
\text { Clonazepam }\end{array}$ \\
\hline Partial Seizures & $\begin{array}{l}\text { Carbamazepine } \\
\text { Phenytoin } \\
\text { Oxcarbazepine } \\
\text { Valproic Acid }\end{array}$ & $\begin{array}{l}\text { Gabapentin* } \\
\text { Phenobarbital } \\
\text { Primidone } \\
\text { Felbamate } \\
\text { Eslicarbazepine } \\
\text { Vigabatrin* } \\
\text { Lacosamide* } \\
\text { Pregabalin } \\
\text { Levetiracetam* } \\
\text { Rufinamide* }\end{array}$ \\
\hline $\begin{array}{c}\text { Atypical Absence } \\
\text { Myoclonic, and Atonic } \\
\text { Seizures }\end{array}$ & $\begin{array}{l}\text { Valproic acid } \\
\text { Lamotrigine } \\
\text { Topiramate }\end{array}$ & $\begin{array}{l}\text { Clonazepam } \\
\text { Felbamate }\end{array}$ \\
\hline
\end{tabular}

\section{Valproic acid (Sodium valproate):}

Sodium valproate is a wide range of AEDs with a particular value in idiopathic generalized epilepsy and effective throughout the entire range of seizures, used mainly for treating the generalized tonic clonic seizures in paediatric patients [55]. Valproate is named after the valproic acid which has been transformed to the form that functions in the body. The valproic acid dissociates in the gastrointestinal tract in to the valproate ion. In adults and teens, the starting dose of sodium valproate is $500 \mathrm{mg} /$ day for 1 to 2 weeks, with increase in dose to $500 \mathrm{mg}$ twice a day [56]. Sodium valproate was known to produce mild liver toxicity in epileptic children [57].

\section{Carbamazepine:}

For focal seizures and general tonic-clonic seizures, carbamazepine, a tricyclic antidepressant is indicated. It is not successful and can be injurious for some individuals who have absences [58]. The low dose carbamazepine of about 100/200 mg daily should be taken as a potent auto inducer, which allows tolerance for its side effects on CNS. Carbamazepine seems to be functioning by decreasing the polysynaptic responses and obstruct post-tetanic potentiation. Carbamazepine can cause a 
variety of unusual reactions, the most frequent being a skin rash, in up to $10 \%$ of people exposed to this disease [59].

\section{Phenytoin:}

Phenytoin, because of its persistent toxicity and kinetic profile, is now a final alternative for focal and tonic-clonic seizures. The motor cortex seems to be the primary site of activity, where the drug prevents seizure development. Phenytoin is among a handful of therapeutic drugs that turn from first-line kinetics to saturation kinetics [60]. Phenytoin may help to stabilize the hyperexcitability threshold caused by excess stimulation or environmental changes that can reduce the membrane sodium gradient by promoting a sodium influence on the neurons. This behavior includes reducing post-tetanic potential at synapses. Use of an intravenous (IV) phenytoin is unacceptable in adults who require quick, steady-state serum levels. Phenytoin decreases the total activity of the tonic stage of tonic-clonic seizures at brainstem sites. Phenytoin is a target for medicines such as allopurinol, amiodarone, cimetidine because of their saturated metabolism [61].

\section{Phenobarbital:}

Focal and tonic-clonic seizures have been treated by Phenobarbital but are rarely used in developing countries now a days due to their ability for neurotoxicity. A minimum dose of about $30 \mathrm{mg}$ in adolescents and adults should be initiated to reduce sedation and can be gradually increased according to clinical criteria of dose 15-30 mg [62].

\section{Clonazepam:}

A benzodiazepine derivative, Clonazepam is protective against absences, myoclonic jerks and tonic-clonical seizures but its usage is decreased due to its tolerance and sedation. Up to 30 per cent of patients in certain trials have shown a lack of activity commonly within three months. Benzodiazepines' antiseizure activity contributes primarily to their ability to improve $\mathrm{Cl}-$ conductance due to GABA enhancement. Some patients will respond correctly to this drug but almost $50 \%$ will intensify the attacks when it is withdrawn. The maximum recommended daily dose is $20 \mathrm{mg}$ [63].

\section{Ethosuximide:}

Ethosuximide is an antiseizure succinimide, which is classified as alpha-ethyl-alpha methyl-succinimide. This suppresses the 3cycle $(3-\mathrm{Hz})$ pick-and-wave paroxytic behavior linked with consciousness deficits, which are normal in the absence seizures. Clearly, impairment of the cortex and increase of the CNS threshold to invasive stimuli reduces the frequency of epileptic attacks [64]. Slow implementation is 
susceptible to minimize gastrointestinal and CNS adverse effects. When other seizures coexist with absence epilepsy, ethosuximide can be provided in addition with other AEDs. The starting dose of $500 \mathrm{mg}$ daily is practical with developmental raise of 1-2 g / day as required. Based on clinical necessity, the dosage can be increased every 2 to 4 weeks [65].

\section{DEVELOPING AGENTS}

Eslicarbazepine Acetate: Derivative of carbamazepine, a new anticonvulsant CNSactive medicinal drug. For adults with refractive, partial initial convulsions, it is intended as a supplementary therapy. ESL has been linked to a significant reduction in seizure frequency in clinical trials in comparison with placebo in partial-accident epilepsy patients. As an adjunctive therapy for adult with partial seizures in March 2009, ESL was submitted for approval by FDA [66]. The New Drug Application (NDA) was licensed for approval and was formally reviewed by the FDA. ESL was given to patients with partial seizures once daily at dose levels of $400 \mathrm{mg}, 800 \mathrm{mg}$ or $1200 \mathrm{mg}$ [67].

Retigabine: A potassium-channel opener of the first level in neurons, retigabine as an adjunctive therapy is in final stage of development as a partial onset seizure. In
October 2009, Valeant and GSK submitted an NDA for retigabine to the FDA. Specific adverse events (at a frequency above or equal to $5 \%$ and double that of placebo) in all completed trials to date were dizziness and fatigue, vertigo, tremor, abnormal coordination, respectively. The drug is currently under review by the FDA for approval [68].

Other drugs: The treatment of Lennox Gaustaut Syndrome is being studied with Clobazam and perampanel (E2007, Eisai), as potential intervention therapy for partiallyaccident seizure patients, is being developed. Fluorofelbamate, Valrocemide, Carisbamate, Licarbazepine are the some other newly developing drugs [69].

\section{REFERENCES}

[1] Sridharan R, Murthy BN. Prevalence and pattern of epilepsy in India. Epilepsia 1999; 40(5): 631-6.

[2] Leonardi M, Ustun TB. The global burden of epilepsy. Epilepsia 2002; 43 (Suppl 6): 21-5.

[3] Janani S, Geetha $P$ and Shanmugasundaram P. DiabetesEpilepsy Symbiosis. Res J Pharm Technol 2017; 10(1): 351-354.

[4] Parag Jain, Anand Surana, Ravindra Pan dey and Shiv Shankar Shukla. Epilepsy: A Neurological Cramp. Res J Pharmacol Pharmacodyn 2013; 5(1): 1-5. 
[5] Tamilselvan T, Arokia Rani C, Ashna Raj, Leena Priya M, Nissy Varghese and Sojan P. Paul. Prescription Analysis of Antiepileptic Drugs in a Tertiary Care Hospital. Asian J Pharm Tech 2018; 8(1): 43-46.

[6] Pahl K, de Boer H. Epilepsy and rights. In: World Health Organization. Atlas: Epilepsy Care in the World 2005, illustrated edition. Geneva, Switzerland: WHO Publications; 2005. 72-3.

[7] Berg AT, Shinnar S. The risk of seizure recurrence following a first unprovoked seizure: A quantitative review. Neurology 1991; 41: 965-967.

[8] Kale R. Bringing epilepsy out of the shadows. BM Journal 1997; 315(7099): 2-3.

[9] Keziya Ann Mammenand and Sathesh Kumar S. A Prospective Observational Study on Depression in Epileptic Patients. Res J Pharm Tech 2017; 10(8): 2587-2590.

[10] Engel Jr, International League against Epilepsy (ILAE). A proposed diagnostic scheme for people with epileptic seizures and with epilepsy: Report of the ILAE task force on classification and terminology. Epilepsia 2001; 42: 796-803.

[11] Karis JP. Epilepsy. Am J Neuroradio 2008; 29(6): 1222-1224.

[12] Christensen J, Sidenius P. Epidemiology of epilepsy in adults:
Implementing the ILAE classification and terminology into population-based epidemiologic studies: Epidemiologic epilepsy studies. Epilepsia 2012;53:147

[13] So EL. Classifications and epidemiologic considerations of epileptic seizures and epilepsy. Neuroimaging Clin N Am 1995; 5:51326

[14] Kim JH. Pathology of seizure disorders. Neuroimaging Clin $\mathrm{N}$ Am 1995; 5: 527-45.

[15] Lowenstein DH. Seizures and epilepsy. In: Fauci AS, Kasper DL Longo DL, eds. Harrison's Principles of Internal Medicine, 17th ed. Section 2: Diseases of the Central Nervous System. New York: McGraw-Hill; 2008; 2498-2512.

[16] Bazil CW, Morrell MJ, Pedley TA. Epilepsy. In: Rowland LP, ed. Merritt's Neurology, 11th ed. Philadelphia: Lippincott Williams \& Wilkins; 2005; 990-1008.

[17] Hauser WA, Hesdorffer DC. Epilepsy: frequency, causes and consequences. New York: Demos; 1990: 1-51.

[18] Ben-Ari Y, Holmes GL. Effects of seizures on developmental processes in the immature brain. Lancet Neurol 2006; 5: 1055-1063.

[19] Michel B, Asla P. Research priorities in epilepsy for the next decade-a representative view of the European 
scientific community. Epilepsia 2009; 50(3): 571-578.

[20] Engel J Jr. 2013. Seizures and epilepsy. Oxford University Press, Oxford.

[21] Beghi E, Carpio A, Forsgren L, Hesdorffer DC, Malmgren K, Sander $\mathrm{JW}$, et al. Recommendation for a definition of acute symptomatic seizure. Epilepsia 2010; 51: 671-5.

[22] Ropper AH, Samuels MA. Epilepsy and other seizure disorders. In: Adams and Victor's Principles of Neurology, $9^{\text {th }}$ Ed. New York: McGraw-Hill Medical; 2009: 304-338.

[23] Davis R, Dalmau J. Autoimmunity, seizures, and status epilepticus. Epilepsia 2013; 54: 46-49.

[24] Dudek FE, Sutula TP. Epileptogenesis in the dentate gyrus: A critical perspective. Prog Brain Res 2007; 163: $755-773$.

[25] Engel J Jr, Pedley TA. (ed.). 2008. Epilepsy: A comprehensive textbook. Wolters Kluwer, Philadelphia.

[26] HolmesG, Ben-Ari Y. 1998. Seizures in the developing brain: Perhaps not so benign after all. Neuron 21: 1231-1234.

[27] Dania E Ibrahim, Wisam Kadhum H Alhashemi, Sajid Ibrahim Alhussaini. Study of Docosahexaenoic Acid and Eicosapentanoic Acid Effects on Some Biochemical Parameters in Epileptic patients. Res J Pharm Tech 2020; 13(1): 319-322.
[28] Padakandla Sai Teja, K. Narsimhan. Automated detection of Epilepsy using Wavelet Features. Res J Pharm Tech 2015; 8(12): 1619-1624.

[29] Dayani MA, Abdolhadi Daneshi, Reza Ahadi, Babak Shekarchi and Daryoush Fatehi. Diagnostic Value of magnetic resonance spectroscopy in Morphometrical Analysis of basal ganglia in patients with Idiopathic Generalized Epilepsy. Res J Pharm Tech 2017; 10(8): 2693-2696.

[30] Wieshmann UC. Clinical application of neuroimaging in epilepsy. $\mathrm{J}$ Neurol Neurosurg Psychiatry 2003; 74: 46670.

[31] Firkin, A. L. et al. Mind the gap: Multiple events and lengthy delays before presentation with a 'first seizure'. Epilepsia 2015; 56, 15341541.

[32] Caruso PA, Johnson J, Thibert R, Rapalino O, Rincon S, Ratai EM. The use of magnetic resonance spectroscopy in the evaluation of epilepsy. Neuroimaging Clin N Am 2013; 23: 407-424.

[33] Kim H, Paige AL, Knowlton RC. Advances in structural and functional neuroimaging: How are these guiding epilepsy surgery In Epilepsy: Mechanisms, models, and translational perspectives (ed. Rho JM, Sankar R, 
Stafstrom CE), 2010; pp. 257-282.

CRC, Boca Raton, FL.

[34] Wiebe, S., Téllez-Zenteno, J. F. \& Shapiro, M. An evidence-based approach to the first seizure. Epilepsia 2008; 49, 50-57.

[35] Kay B, Szaflarski JP. 2014. EEG/fMRI contributions to our understanding of genetic generalized epilepsies. Epilepsy Behav 2014; 34: 129-135.

[36] Pohlmann-Eden, B. The first seizure and its management in adults and children. BMJ 2006; 332, 339-342.

[37] Leach JP, Brodie MJ. New antiepileptic drugs-an explosion of activity. European J Epilepsy 1995; 4(1): 5-17.

[38] Cortez MA, McKerlie C, Snead OC. A model of atypical absence seizures: EEG, pharmacology, and developmental characterization. Neurology 2001; 56: 341-349.

[39] Boylan LS, Flint LA, Labovitz DL et al. Depression but not seizure frequency predicts quality of life in treatment-resistant epilepsy. Neurology 2004; 62: 258-261.

[40] Schierhout G, Roberts I. Prophylactic antiepileptic agents after head injury: a systematic review. J Neurol Neurosurg Psychiatry 1998; 64: 108-12.

[41] Jithendra Chimakurthy, Talasila EGK Murthy and Lokesh Upadhyay. Effect of Curcumin on Sub-Therapeutic Doses of AED'S And Long-Term Memory in
MES Induced GTC Type of Seizures in Rats. Res J Pharm Tech 2008; 1(4): 401-404.

[42] Goldenberg MM. Overview of Drugs Used For Epilepsy and Seizures. Pharm Therapeutics 2010; 35(7): 392-415.

[43] Campbell E, Kennedy F, Russell A et al. Malformation risks of antiepileptic drug monotherapies in pregnancy: updated results from the UK and Ireland Epilepsy and Pregnancy Registers. J Neurol Neurosurg Psychiatry 2014; 85:1029-1034.

[44] Marson AG, Al-Kharusi AM, SANAD Study group: The SANAD study of effectiveness of carbamazepine, gabapentin, lamotrigine, oxcarbazepine, or topiramate for treatment of partial epilepsy: an unblinded randomized controlled trial. Lancet 2007; 369: 1000-1015.

[45] Reynolds EH, Shorvon SD. Single drug or combination therapy for epilepsy? Drugs. 1981; 21: 374-382.

[46] Privitera M. Large clinical trials in epilepsy: funding by the NIH versus pharmaceutical industry. Epilepsy Res. 2006: 52-56

[47] Reynolds EH. Polytherapy, monotherapy, and carbamazepine. Epilepsia. 1987; 28(Suppl 3): S77-S80.

[48] Giussani G, Beghi E: Does mechanism of drug action matter to inform rational polytherapy in epilepsy? CNS Neurol 
Disord Drug Targets 2013; 12: 426435.

[49] Brodie MJ, Barry SJ, Bamagous GA, Norrie JD, Kwan P: Patterns of treatment response in newly diagnosed epilepsy. Neurology 2012; 78: 1548 1554.

[50] A rif H, Buchsbaum R, Weintraub D, Pierro J, Resor SR Jr, Hirsch LJ: Patient-reported cognitive side effects of antiepileptic drugs: predictors and comparison of all commonly used antiepileptic drugs. Epilepsy Behav 2009; 14: 202-209.

[51] 51. Section 2: Diseases of the Central Nervous System: Lowenstein DH. Seizures and epilepsy. In: Fauci A, Braunwald E, Kasper D, Hauser S, Longo D, Jameson J, et al editors. Harrison's principles of internal medicine.17th ed. Newyork: Mcgrawhill; 2008. p. 2498-2512.

[52] Musicco M, Beghi E, Solari A, et al. Treatment of first tonic-clonic seizure does not improve the prognosis of epilepsy. First seizure trial group (FIRST group). Neurology 1997; 49: 991-8.

[53] Deckers, C.L.P.; Czuczwar, S.J.; Renier, W.O.; van Rijn, C.M. Selection of antiepileptic drug polytherapy based on mechanism of action: the evidence reviewed. Epilepsia 2000, 41, 13641374.
[54] Antkiewicz-Michaluk, L. Receptor and voltage-operated ion channels in the central nervous system. Pol. J. Pharmacol. 1995. 47, 253-264.

[55] Pathan Muzammil Khan, Jha Asha, Pat hak Swanand, Jha Rajesh, Khond Sachi $\mathrm{n}$ and Mujawar Jahir. Antiepileptic Drug Utilization in Pediatric Patients at a Tertiary Care Rural Teaching Hospital of Central India. Res J Pharmacol Pharmacodyn 2015; 7(1): 510.

[56] Trojnar MK, Wierzchowska-Cioch E, Krzyzanowski M, Jargiełło M, Czuczwar SJ. New generation of valproic acid. Pol J Pharmacol 2004; 56: 283-288.

[57] Sangeetha N and Mahadeva Rao US. Hepatotoxic Effect of Sodium Valproate Therapy in Epileptic Children. Research Journal of Pharmaceutical Dosage Forms and Technology 2011; 3(4): 135-138.

[58] Dalby, M. A. Antiepileptic and psychotropic effect of carbamazepine (Tegretol) in the treatment of psychomotor epilepsy. Epilepsia, 1971; 12, 324-325.

[59] Hassan, M. N., and Parsonage, M. J. Experience in the long term use of carbamazepine in the treatment of epilepsy. Eighth International Symposium, 1976; pp. 35-44. Edited by J. K. Penry. Raven Press: New York. 
[60] López Marisol, Dorado, Pedro Monroy. (2011). Pharmacogenetics of the antiepileptic drugs phenytoin and lamotrigine. Drug metabolism and drug interactions. 2011; 26: 5-12.

[61] Phenytoin, package insert. Available at: http://media.pfizer.

com/files/products/uspi_dilantin.pdf.

Accessed January 25, 2020.

[62] Christiansen, J., and Dam, M. Influence of phenobarbital and diphenylhydantoin on plasma carbamazepine levels in patients with epilepsy. Acta Neurologica Scandinavica, 1973; 49: 543-546.

[63] Browne, T. R., and Penry, J. K. (1973). Benzodiazepines in the treatment of epilepsy. Epilepsia (Amsterdam), 1973; 14: 277-310.

[64] White SH. Comparative anticonvulsant and mechanistic profile of the established and new antiepileptic drugs. Epilepsia 1999; 40(Suppl 5): 2-10.

[65] Coulter DA, Huguenard JR, Prince DA. Characterization of ethosuximide reduction of low-threshold calcium current in thalamic neurons. Ann Neurol 1989; 25:582-593.

[66] Almeida L, Soares-da-Silva P. Eslicarbazepine acetate (BIA-2-093). Neurotherapeutics 2007; 4: 88-96.

[67] Talati R, White CM, Coleman CI. Eslicarbazepine: A novel antiepileptic agent designed for improved efficacy and safety. Formulary 2009; 44: 357361.

[68] Retigabine. Available at: www.dancewithshadows.com/pillscribe new-epilepsy-drug-retigabine-underfda-review-in-us. Accessed January 31, 2010.

[69] Advances in anti-epileptic drug therapy. Available at: www. epilepsy foundation. org/ epilepsyusa/ magazine/ Issue2-2009/ Antiepileptic Drug Therapy. cfm. Accessed February 2, 2010 . 